[12] Kelly, E. J. (1986)

An adaptive detection algorithm.

IEEE Transactions on Aerospace and Electronic Systems, AES-22 (1986), 115-127.

[13] Horn, R. A., and Johnson, C. R. (1985)

Matrix Analysis.

New York: Cambridge University Press, 1985.

\section{Analysis and Design of (LC)(LC)-Type Series-Parallel} Resonant Converter

A series-parallel resonant converter employing (LC)(LC)-type tank circuit operating in lagging power factor (PF) mode is presented and analyzed using complex ac circuit analysis. Design curves are obtained and the converter is optimized under certain constraints. Detailed Space Integrated Control Experiment (SPICE) simulation results are presented to evaluate the performance of the designed converter under varying load conditions. Results obtained from an experimental converter are also presented. The results obtained from the theory, SPICE simulation, and the experimental converter are compared. The proposed converter has high efficiency from full load to very light load $(<10 \%)$. Switching frequency variation required for a wide change in the load (near load open circuit to full load) is narrow compared with the series resonant converter (SRC).

\section{INTRODUCTION}

A number of high-frequency (HF) resonant converter configurations have been reported in the literature [1-15]. Series resonant converter (SRC) is the simplest and most well documented configuration [1]. SRCs have high efficiency from full load to part load. But the major disadvantage of the SRC is the difficulty in regulating the converter output voltage at light loads, i.e., they require very wide variation in switching frequency for load regulation.

In an attempt to improve the performance of resonant converters, higher order resonant converters have been proposed (e.g. [3-15]). It has been shown by a number of authors that the LCC-type parallel resonant converter (also called as series-parallel resonant converter [3-6]) has a number of desirable

Manuscript received May 23, 1994; revised January 17, 1995. IEEE Log No. T-AES/31/3/12745.

Part of this work was supported by the UNDP under UNDP/TOKTEN program.

0018-9251/95/\$4.00 (C) 1995 IEEE

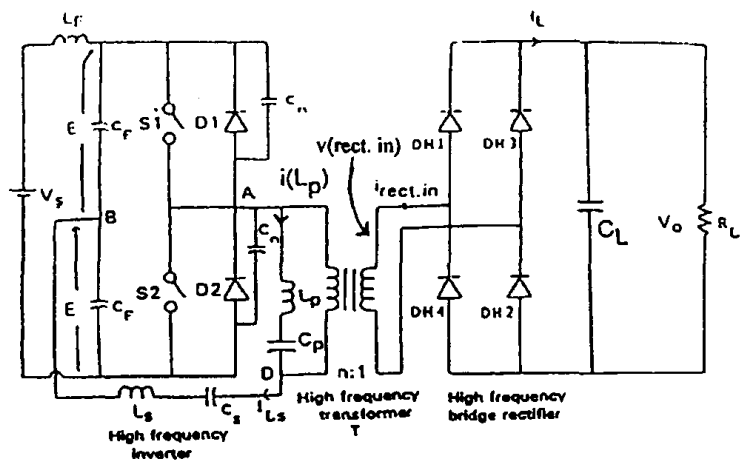

Fig. 1. Basic circuit diagram of (LC)(LC)-type series-parallel resonant converter suitable for operation in lagging $\mathrm{PF}$ mode. (Note: S1 and S2 are HF switches capable of base or gate turn-off capability).

features compared with other resonant converter configurations. Although this converter has good efficiency from full load to about $50 \%$ load, its efficiency falls for loads below about $50 \%$ of rated load since the converter takes the properties of the parallel resonant converter. This is because the peak current through the HF switches does not decrease in proportion to the load for load currents below about $50 \%$ of full load. A modified (LCL-type) SRC presented in [15] has very good characteristics (viz., high efficiency and narrow variation in switching frequency for load regulation), but has higher voltage stress on the output rectifier diodes.

Fig. 1 shows the circuit diagram of the proposed (LC)(LC)-type series-parallel converter. This converter was first proposed for telecommunication applications in [7] and the converter was operated below resonance (leading power factor (PF) mode). This type of operation resulted in audible noise and reduced efficiency. These problems can be overcome by operating the converter in above resonance (lagging PF) mode [5] and optimizing the converter design. Therefore, the objectives of this work are to present a detailed analysis, to obtain design curves for lagging PF mode of operation, to select the component values for an optimized converter, and to present detailed simulation and experimental results for the proposed converter.

The layout is as follows. Section II presents the operation of the converter. The converter is analyzed using complex ac circuit analysis in Section III. The design procedure is illustrated by a design example in Section IV. The converter is optimized under certain constraints. The converter designed in Section IV is simulated using the Space Integrated Circuit Experiment (SPICE) simulation program in Section V. Detailed experimental results obtained from a $100 \mathrm{~W}$ experimental converter are presented in Section VI to verify the theory. 


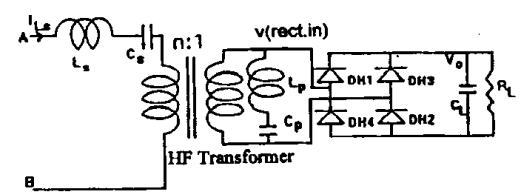

(a)

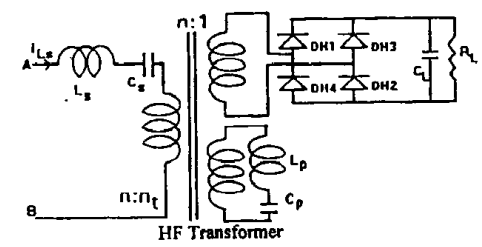

(b)

Fig. 2. Alternate possible connections of parallel resonant branch in Fig. 1. Parallel branch placed on (a) secondary-side of HF transformer, (b) on tertiary winding.

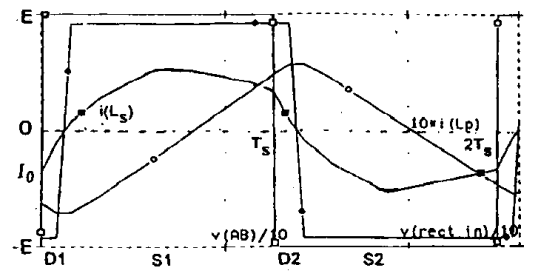

Fig. 3. Typical operating waveforms to illustrate lagging PF mode of operation for converter shown in Fig. 1.

\section{OPERATING PRINCIPLE}

Fig. 1 shows the basic circuit diagram of (LC)(LC)-type series-parallel resonant converter. Capacitive output filter is used. One can also place the parallel resonant circuit $\left(L_{p} C_{p}\right)$ either on the secondary-side (Fig. 2(a)) of the HF transformer or on a tertiary-winding (Fig. 2(b)). With these arrangements, the leakage inductances of the HF transformer can be utilized as part of resonating inductor(s). The operating principle of the converter can be understood by referring to the typical operating waveforms (obtained from SPICE simulation) shown in Fig. 3. The converter is operated in the lagging PF mode (above resonance mode) with D1 (or D2) conducting prior to the turn-on of $\mathrm{S} 1$ (or $\mathrm{S} 2$ ) resulting in zero voltage turn-on of $\mathrm{S} 1$ and $\mathrm{S} 2$. The voltage input at the rectifier input terminals is nearly a square-wave with an amplitude nearly equal to the output load voltage.

\section{STEADY-STATE ANALYSIS}

In this section, the (LC)(LC)-type series-parallel resonant converter is analyzed using complex ac circuit analysis method [5, 9]. This approach gives good design values as verified in this work. Expressions for the

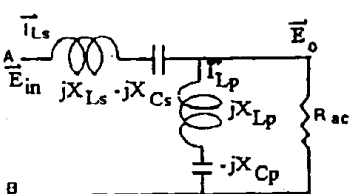

Fig. 4. Phasor circuit model used for analysis of (LC)(LC)-type converter shown in Fig. 1. (Note: $X_{L s}, X_{C s}, X_{L p}, X_{C_{p}}$ are reactances of $L_{s}, C_{s}, L_{p}$, and $C_{p}$, respectively.)

converter gain and component ratings are derived in this section. Once the converter is designed at full load using this simple analysis, its performance can be evaluated using SPICE simulation as done in Section V.

\section{A. Assumptions Used}

The following assumptions are made in the analysis presented in this work.

1) The switches, diodes, inductors, capacitors, and snubber components are ideal.

2) The effect of snubbers is neglected.

3) The HF transformer is ideal.

4) The input voltage to the resonant circuit is represented by the fundamental component of voltage across AB. Similarly, only fundamental component of the voltage at the input of the rectifier is taken into consideration.

\section{B. Modeling of the Converter}

The rectifier-filter-load block in Figs. 1 and 2 can be replaced by an equivalent ac resistance $[5,9]$, $R_{a c}$, considering the fundamental components of the waveforms (assumption 4). The value of $R_{a c}$ is given by $[5,9]$

$$
R_{a c}=\left(8 / \pi^{2}\right) R_{L}^{\prime} \Omega
$$

where $R_{L}^{\prime}$ is the primary-side reflected load resistance given by

$$
R_{L}^{\prime}=n^{2} R_{L} \Omega
$$

Fig. 4 shows the phasor circuit model used for the analysis. Based on this model, the steady-state analysis of the converter using complex ac circuit analysis is presented in the next section.

\section{Analysis}

All the equations presented are normalized using the base quantities:

$$
V_{B}=E, \quad Z_{B}=R_{L}^{\prime}, \quad I_{B}=V_{B} / Z_{B} .
$$

The normalized quantities are represented by additional subscript " $p u$ ". 
Following the procedure presented in $[5,9]$ and using complex circuit analysis in Fig. 4, it can be shown that the output voltage of the converter referred to the primary-side (i.e., converter gain) is given by

$$
M=1 /\left[\left(X_{s p u} / K\right) 2+\left(1+X_{s p u} / X_{p p u}\right)^{2}\right]^{1 / 2} \text { p.u. }
$$

where

$$
\begin{aligned}
K & =8 / \pi^{2} \\
X_{s p u} & =Q_{s} f_{s s n}-Q_{s} / f_{s s n} \text { p.u. } \\
X_{p p u} & =Q_{p} f_{s p n}-Q_{p} / f_{s p n} \text { p.u. } \\
Q_{s} & =\left(L_{s} / C_{s}\right)^{1 / 2} / R_{L}^{\prime} \\
f_{s s n} & =\omega_{s} / \omega_{s r}=f_{s} / f_{s r} \\
\omega_{s r} & =1 /\left(L_{s} C_{s}\right)^{1 / 2} \mathrm{rad} / \mathrm{s} \\
Q_{p} & =\left(L_{p} / C_{p}\right)^{1 / 2} / R_{L}^{\prime}=Q_{s}\left(L_{p} / L_{s}\right)^{1 / 2}\left(C_{s} / C_{p}\right)^{1 / 2}
\end{aligned}
$$

$$
f_{s p n}=f_{s} / f_{p r}=\omega_{s} / \omega_{p r}=f_{s s n}\left(L_{p} / L_{s}\right)^{1 / 2}\left(C_{p} / C_{s}\right)^{1 / 2}
$$

$$
\omega_{p r}=1 /\left(L_{p} C_{p}\right)^{1 / 2} \mathrm{rad} / \mathrm{s}
$$

and $f_{s}$ is the switching frequency.

The equivalent impedance $Z_{e q}$ (in per unit) looking into the terminals $A B$ is given by

$$
Z_{\text {eqpu }}=\left[B_{1}+j B_{2}\right] \text { p.u. }
$$

where

$$
\begin{aligned}
& B_{1}=(1 / K)(1 / D) \\
& B_{2}=X_{s p u}+\left(1 / X_{p p u}\right)(1 / D) \\
& D=\left(1 / K^{2}\right)+\left(1 / X_{p p u}^{2}\right) .
\end{aligned}
$$

The inverter output peak current (same as the switch peak current) is given by

$$
I_{L s p p u}=4 /\left[\pi\left|Z_{e q p u}\right|\right] \text { p.u. }
$$

The per unit value of the initial current $I_{0}$ (at $t=0$, Fig. 3) is given by

$$
I_{0 p u}=I_{L s p p u} \sin (-\phi) \text { p.u. }
$$

where

$$
\phi=\tan ^{-1}\left[B_{2} / B_{1}\right] \text { rads. }
$$

The peak voltage across the capacitor $C_{s}$, the peak current through the parallel branch (i.e., through inductor $L_{p}$ and capacitor $C_{p}$ ), and the peak voltage across $C_{p}$ are

$$
\begin{aligned}
V_{C s p p u} & =X_{C s p u} \cdot I_{L s p p u} \text { p.u. } \\
I_{L p p p u} & =I_{L s p p u} /\left[1+\left(X_{p p u} / K\right)^{2}\right]^{1 / 2} \text { p.u. } \\
V_{C_{p p p u}} & =X_{C_{p p u}} \cdot I_{L p p p u} \text { p.u. }
\end{aligned}
$$

\section{DESIGN}

Using the analysis presented in Section III, design curves are obtained for various ratios of $L_{s} / L_{p}$ and $C_{s} / C_{p}$. This is illustrated by a design example. The specifications of the half-bridge converter design are: input supply voltage $2 E=100 \mathrm{~V}$, output power $P_{0}=$ $100 \mathrm{~W}$, load voltage $V_{0}=48 \mathrm{~V}$, switching frequency $f_{s}=100 \mathrm{kHz}$.

The total kVA rating of the tank circuit per $\mathrm{kW}$ of output power, converter gain $(M$, p.u. $)$, and inverter output peak current, with variation in $f_{s s n}$ (ratio of switching frequency to series resonance frequency) are plotted in Figs. 5(a)-(c) for different ratios of $L_{s} / L_{p}$ and $C_{s} / C_{p}$. These curves are obtained for maximum power output condition and for lagging PF mode of operation. $I_{0}$ (using (19)) must be negative for lagging PF mode of operation.

The converter is optimized for 1) minimum $\mathrm{kVA}$ rating of tank circuit per $\mathrm{kW}$ of output power, 2) minimum inverter output peak current, and 3) minimum variation in switching frequency for full load to no load voltage regulation.

It can be observed that for a given $Q_{s}$ and $f_{s s n}$, as the value of $L_{s} / L_{p}$ increases (Fig. 5(a1)-(a3)), $\mathrm{kVA} / \mathrm{kW}$ rating of the tank circuit increases (i.e., tank circuit size increases). However, the switching frequency variation required for voltage regulation decreases (Fig. 5(b1)-(b3)). For low inverter output peak current (same as the switch peak current), switching frequency must be nearly equal to the series resonance frequency (with some margin for ensuring enough turn-off time for the switches), i.e., $f_{s s n}$ must be nearly equal to 1 (Fig. 5(c1)-(c3)). Lower inverter output peak current increases the efficiency of the converter. In addition, it can be observed that the $\mathrm{kVA} / \mathrm{kW}$ rating decreases with the value of $Q_{s}$. This also decreases the inverter output peak current at full load.

Based on the optimization constraints and the observations made from the design curves, the following values were selected in the design example:

$$
\begin{aligned}
L_{s} / L_{p} & =0.1, \quad C_{s} / C_{p}=2, \\
Q_{s} & =1, \quad f_{s s n}=1.05 .
\end{aligned}
$$

The normalized output voltage (using (4) or Fig. $5(\mathrm{~b} 2))$ at full load is

$$
M=0.9818 \text { p.u. }
$$




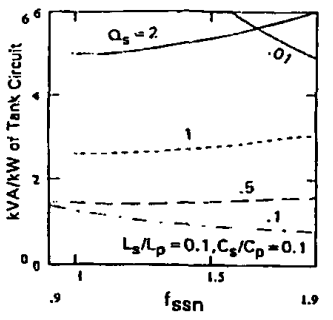

(a1)

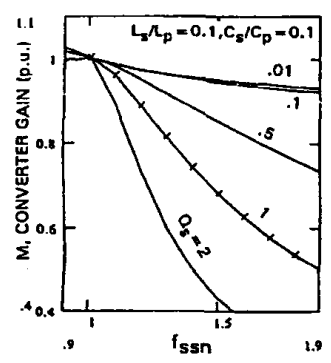

(b1)

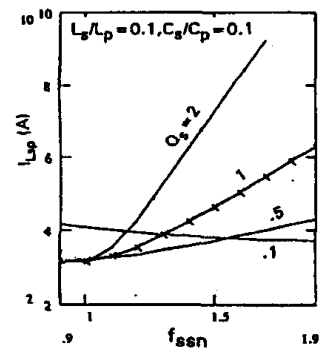

(c1)

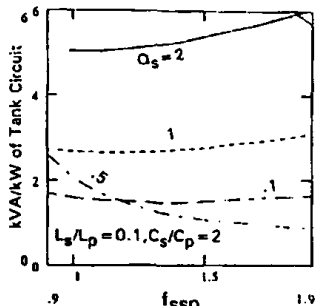

(a2)

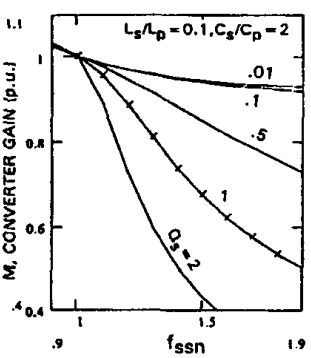

(b2)

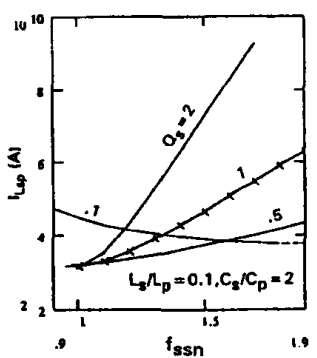

(c2)

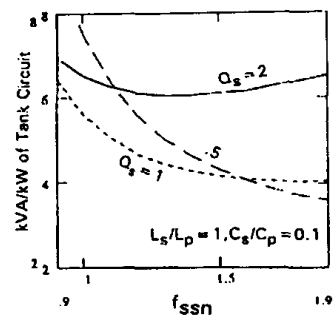

(a3)

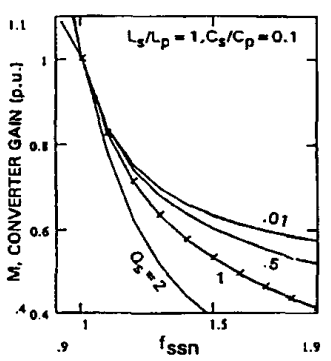

(b3)

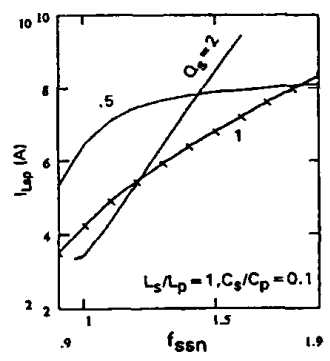

(c3)

Fig. 5. Design curves obtained for the design example. (a) Total kVA rating of tank circuit per $\mathrm{kW}$ of output power for variation in normalized switching frequency, $f_{s s n}$ (ratio of switching frequency to series resonance frequency) for various inductor and capacitor ratios, (a1) $L_{s} / L_{p}=0.1, C_{s} / C_{P}=0.1$, (a2) $L_{s} / L_{p}=0.1, C_{s} / C_{p}=2$, (a3) $L_{s} / L_{p}=1, C_{s} / C_{p}=0.1$. (b) Converter gain $M$ (p.u.) versus $f_{s s n}$ for various inductor and capacitor ratios. (c) Inverter output peak current $\left(I_{L s p}, A\right)$ versus $f_{s s n}$ for various inductor and capacitor ratios for designed $100 \mathrm{~W}$ converter.

The base values given by (3) are used. Then,

$$
V_{0}^{\prime}=49.1 \mathrm{~V} \quad \text { and } \quad R_{L}^{\prime}=24.1 \Omega .
$$

Therefore, the HF transformer turns ratio, $n \cong 1$.

The values of $L_{s}$ and $C_{s}$ are calculated by solving

$$
\begin{aligned}
\left(L_{s} / L_{p}\right)^{1 / 2} & =Q_{s} \times R_{L}^{\prime}=1 \times 24.1 \Omega \\
\omega_{s r} & =1 /\left(L_{s} C_{s}\right)^{1 / 2}=2 \pi f_{s} / f_{s s n} \\
& =2 \pi \times 100,000 / 1.05 \mathrm{rad} / \mathrm{s} .
\end{aligned}
$$

Solution of the above equations gives

$$
L_{s}=40,27 \mu \mathrm{H} \quad \text { and } \quad C_{s}=0.069 \mu \mathrm{F} \text {. }
$$

Since $L_{s} / L_{p}=0.1$ and $C_{s} / C_{p}=2$ are chosen,

$$
L_{p}=402.7 \mu \mathrm{H} \quad \text { and } \quad C_{p}=0.0345 \mu \mathrm{F} .
$$

The peak value of current to be carried by the switches, the inductor $L_{s}$, and the capacitor $C_{s}$ at full load is given by (18),

$$
I_{L s p}=3.21 \mathrm{~A} .
$$

The peak voltage across $L_{s}$, the peak current through $L_{p}$, and the peak voltage across $C_{p}$ (using (21)-(23)) are approximately given by

$V_{C s p}=73.8 \mathrm{~V}, \quad I_{L p p}=0.213 \mathrm{~A}, \quad V_{C p p}=13.9 \mathrm{~V}$ 

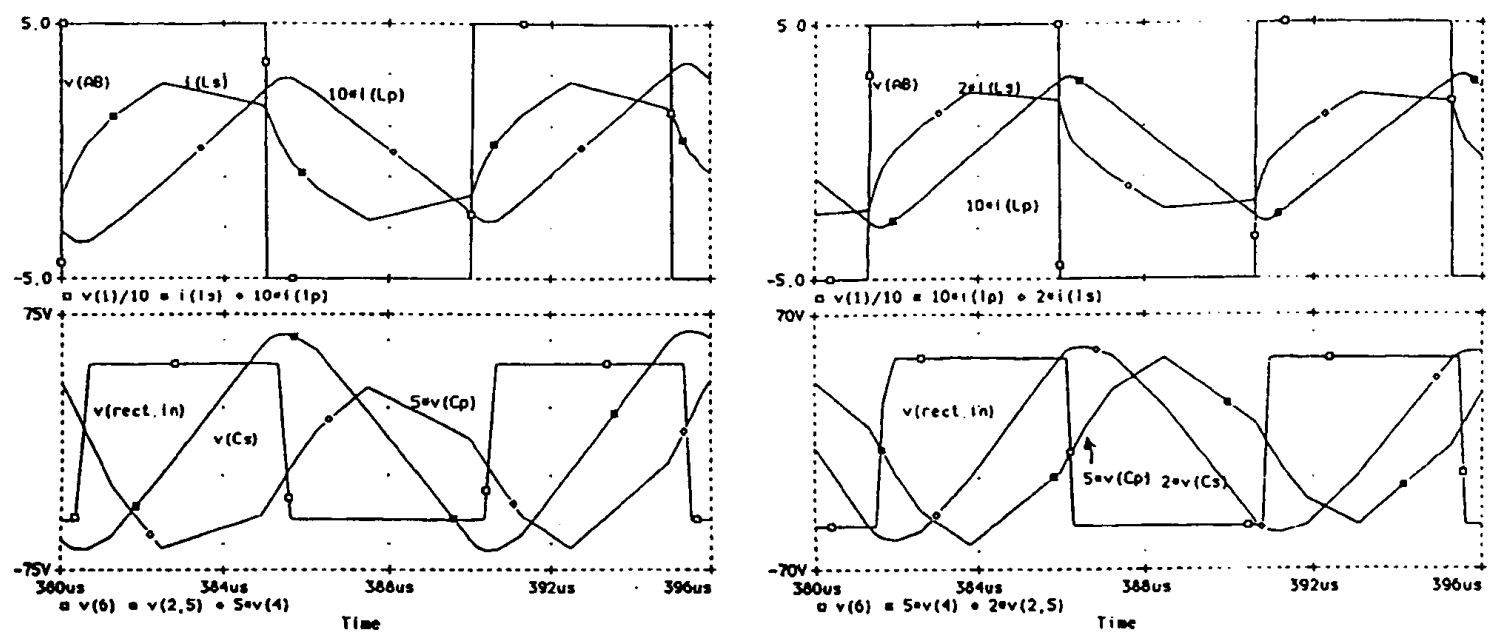

(a)

(b)

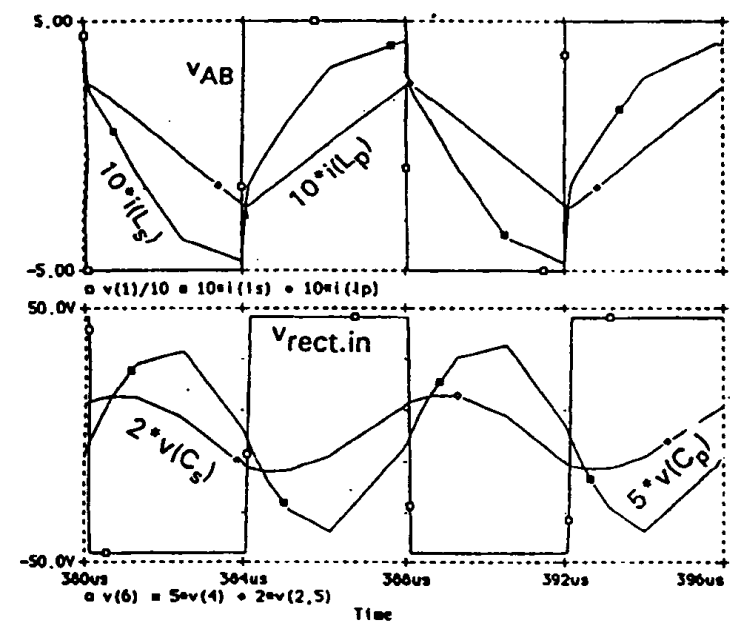

(c)

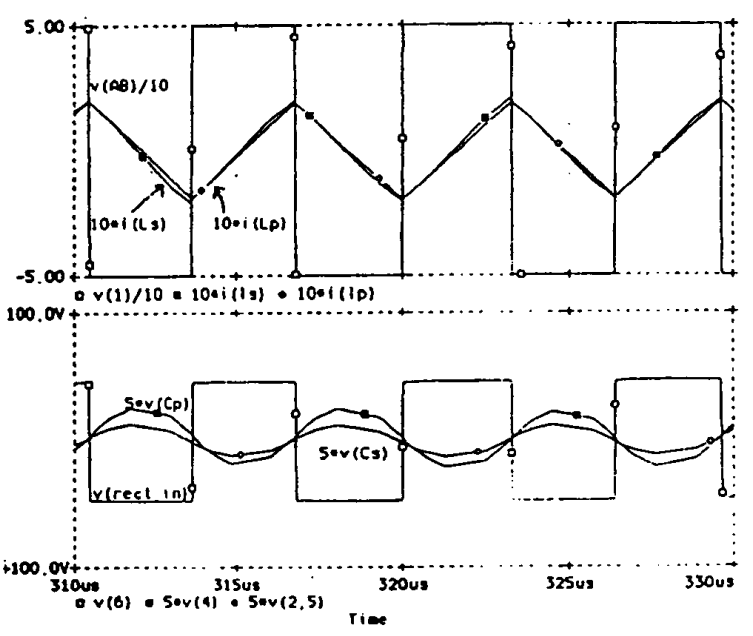

(d)

Fig. 6. Waveforms obtained from SPICE simulation for designed converter. Component values used in simulation correspond to design example. (a) Full-load, $R_{L}^{\prime}=24.1 \Omega$. (b) Half-load, $R_{L}^{\prime}=48.2 \Omega$. (c) $10 \%$ rated load, $R_{L}^{\prime}=241 \Omega$. (d) Almost load open circuit, $R_{L}^{\prime}=241 \mathrm{M} \Omega$.

\section{SPICE SIMULATION RESULTS}

The converter designed in Section IV has been simulated using SPICE program for varying load conditions. Fig. 6 shows some of the waveforms obtained for full load to almost load open circuit condition. In all these waveforms, switching frequency was adjusted (after a number of simulation runs) such that load voltage remains the same as the value obtained at full load. It is clear from these waveforms that the variation in switching frequency required is narrow and the inverter output peak current reduces almost in proportional to the load. Under no load condition, current through $L_{s}$ is the same as current through $L_{p}$. Table I summarizes the results obtained from the simulation.

\section{EXPERIMENTAL RESULTS}

The results obtained from an experimental converter are presented in this section. The details of the $100 \mathrm{~W}$ experimental converter built using the metal-oxide semiconductor field-effect transistors (MOSFETs) as the switches are given in Fig. 7. Typical waveforms obtained from the experimental converter (operating in the lagging PF mode) are shown in Fig. 7 for variations in the load from full load value to very light load (approximately 10\%) condition. In all 


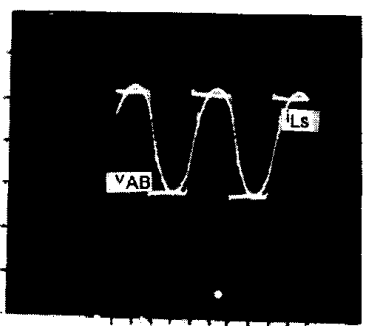

(ai)

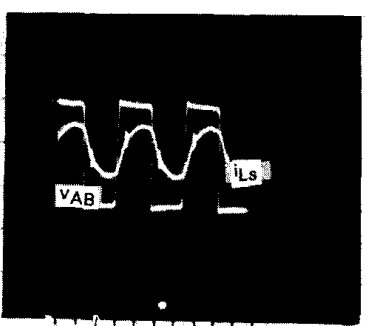

(bi)

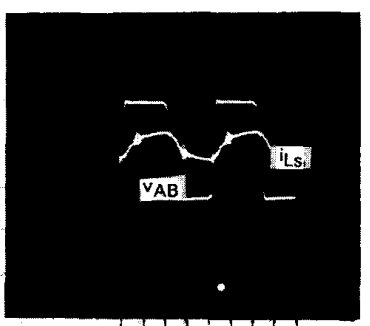

(ci)

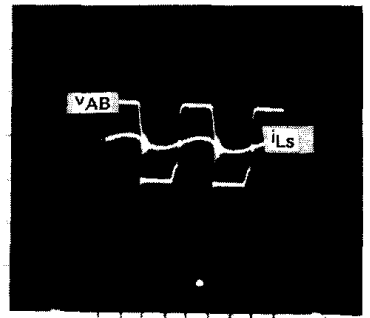

(di)

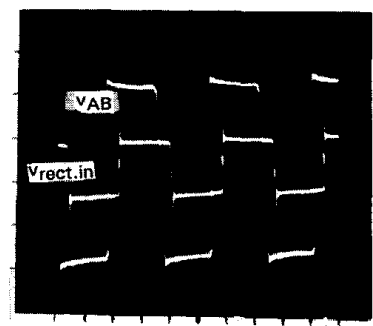

(aii)

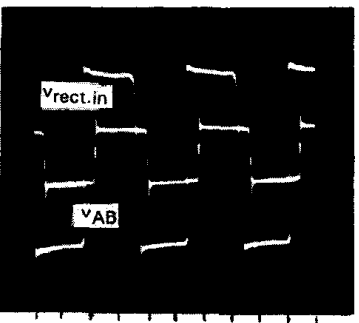

(bii)

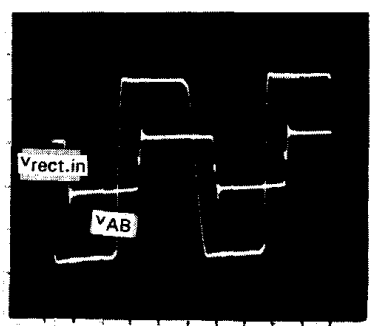

(cii)

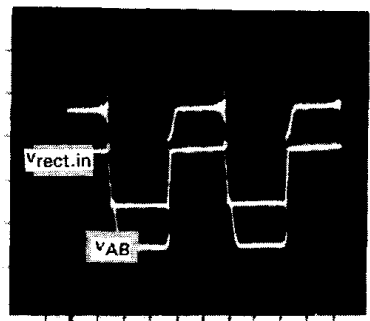

(dii)
Fig. 7. Experimentally obtained waveforms. (a) Full load ( $R_{L}=22 \mathrm{Ohms}$ ). (a1) $\nu_{\mathrm{AB}}(40 \mathrm{~V} /$ div.) and inverter output current $i_{L s}(2.3 \mathrm{~A} /$ div. $),(\mathrm{a} 2) \nu_{\mathrm{AB}}(25 \mathrm{~V} /$ div. $), \nu_{\text {rect.in }}(60 \mathrm{~V} /$ div. $)$, switching frequency, $f_{s} \cong 100 \mathrm{kHz}$. (b) $50 \%$ of full load. (b1) and (b2) same waveforms as (a1) and (a2), $f_{s} \cong 125 \mathrm{kHz}$. (c) $25 \%$ of full load,

(c1) and (c2) same waveforms as (a1) and (a2), $f_{s} \cong 165 \mathrm{kI} \mathrm{z}$.

(d) Approximately $10 \%$ of full load, (d1) and (d2) same waveforms as (a1) and (a2), but $\nu_{\mathrm{AB}}\left(50 \mathrm{~V} /\right.$ div.) in (d1) and $\nu_{\mathrm{AB}}(30 \mathrm{~V} / \mathrm{div}$.) in (d2), $f_{s} \cong 200 \mathrm{kHz}$. (Details of converter. Switches used-IRFP250 MOSFETs, feedback diodes-internal to the

MOSFETs, Input dc voltage, $2 E=100 \mathrm{~V}, L_{s}=76.8 \mu \mathrm{H}$,

$C_{s}=0.033 \mu \mathrm{F}, L_{p}=768 \mu \mathrm{H}, C_{p}=0.33 \mu \mathrm{F}$, rectifier bridge diodes-1N3891.)
TABLE

Summary of Results Obtained From SPICE Simulation for Designed Converter of Section IV

\begin{tabular}{|c|c|c|c|c|}
\hline Parameter & Full-load & $\begin{array}{l}50 \% \text { of } \\
\text { full-load }\end{array}$ & $\begin{array}{l}10 \% \text { of } \\
\text { full-losd }\end{array}$ & Open cireuit \\
\hline$R_{L}^{\prime}(\Omega)$ & 24.1 & 48.2 & 241 & $241 \mathrm{M \Omega}$ \\
\hline $\begin{array}{l}\text { Switching } \\
\text { frequency }(A)(\mathrm{kHz})\end{array}$ & 100 & 107.5 & 125 & 156.25 \\
\hline $\begin{array}{l}\text { Peak current } \\
\text { through } L_{f}\left(I_{L_{r}}\right)\end{array}$ & $2.7 \mathrm{~A}$ & $1.1 \mathrm{~A}$ & $0.46 \mathrm{~A}$ & $0.21 \mathrm{~A}$ \\
\hline $\begin{array}{l}\text { Peak current } \\
\text { through } L_{p}\left(I_{t_{m}}\right)\end{array}$ & $0.32 \mathrm{~A}$ & $0.29 \mathrm{~A}$ & $0.26 \mathrm{~A}$ & $0.21 \mathrm{~A}$ \\
\hline $\begin{array}{l}\text { Peak voltage } \\
\text { across } C_{r}\left(V_{r \rightarrow q}\right)\end{array}$ & $65 \mathrm{~V}$ & $35 \mathrm{~V}$ & $8.3 \mathrm{~V}$ & $3.6 \mathrm{~V}$ \\
\hline $\begin{array}{l}\text { Peak voltage } \\
\text { across } C_{p}\left(V_{t}\right)\end{array}$ & $6.7 \mathrm{~V}$ & $12.1 \mathrm{~V}$ & $7.5 \mathrm{~V}$ & $4.3 \mathrm{~V}$ \\
\hline
\end{tabular}

these waveforms, the output load voltage was held constant at $40 \mathrm{~V}$ (value obtained at the full load). The switching frequency was varied to regulate the output load voltage. It can be easily observed from Fig. 7 that the inverter output peak current decreases from about $3 \mathrm{~A}$ at full load to approximately $0.3 \mathrm{~A}$ at $10 \%$ load. Table II summarizes the experimental results. Table III compares the results obtained from the theory, SPICE simulation and experiment for the full load conditions (component values used correspond to the experimental converter). These results are in reasonably good agreement. It must be noted that component values used in the experimental setup are not the values corresponding to the optimized converter given in the design example. Due to this reason, the switching frequency required is wider than the design example. The above $100 \mathrm{~W}$ experimental converter was used only to illustrate the operating principle of the converter. This converter can be built at higher power levels switching at few hundreds of $\mathrm{kHz}$ with the same performance.

\section{CONCIUSIONS}

In this paper, (LC)(LC)-type series-parallel resonant converter operating in the lagging PF mode has been proposed and analyzed using complex ac circuit analysis method. Analysis presented has been used to obtain design curves. A simple design procedure has been illustrated using a design example of $100 \mathrm{~W}$ converter. Detailed SPICE simulation results have been presented to evaluate the performance of the converter for varying load conditions. It can be observed from the results that the inverter output peak current (same as the switch peak current) reduces with the load current thus having high efficiency even at very light load conditions and, therefore maintains the advantages of the standard SRC. It has also been shown that the converter can operate with load open circuit condition without increasing the frequency to a very high value. It must be noted that 
TABLE II

Summary of Experimental Results

\begin{tabular}{|c|c|c|c|c|}
\hline Parameter & Full-losd & $\begin{array}{l}50 \% \text { of } \\
\text { full-lood }\end{array}$ & $\begin{array}{l}25 \% \text { of } \\
\text { full-load }\end{array}$ & $\begin{array}{l}10 \% \text { of } \\
1 \text { full-loosd }\end{array}$ \\
\hline $\begin{array}{l}\text { Switching } \\
\text { frequency }(B)(\mathrm{kHz})\end{array}$ & 100 & 125 & 165 & 200 \\
\hline $\begin{array}{l}\text { Peak current } \\
\text { through } L_{*}\left(I_{I_{*}}\right)\end{array}$ & $3 \mathrm{~A}$ & $1.5 \Lambda$ & $0.7 \mathrm{~A}$ & $0.3 \wedge$ \\
\hline $\begin{array}{l}\text { Peak current } \\
\text { through } L_{r}\left(I_{I_{m}}\right)\end{array}$ & $0.4 \mathrm{~A}$ & $0.2 \mathrm{~A}$ & $0.1 \wedge$ & $0.05 \AA$ \\
\hline $\begin{array}{l}\text { Peak voltage } \\
\text { across } C_{x}\left(V_{i_{*}}\right)\end{array}$ & $150 \mathrm{~V}$ & $60 \mathrm{~V}$ & $24 \mathrm{~V}$ & $12 \mathrm{~V}$ \\
\hline $\begin{array}{l}\text { Peak voltage } \\
\text { across } C_{p}\left(V_{r_{m}}\right)\end{array}$ & $2.5 \mathrm{~V}$ & $2.5 \mathrm{~V}$ & $2 \mathrm{~V}$ & $2 \mathrm{~V}$ \\
\hline Elficiency & $90.8 \%$ & $91.13 \%$ & $88.6 \%$ & $85.6 \%$ \\
\hline Laed current & $1.82 \mathrm{~A}$ & $0.92 \mathrm{~A}$ & $0.45 \mathrm{~A}$ & $0.2 \Lambda$ \\
\hline
\end{tabular}

Note: Details of converter are given in Fig. $7,2 E=100 \mathrm{~V}$, load voltage, $V_{0}^{\prime}=40 \mathrm{~V}$.

TABLE III

Comparison of Analytical, Simulation and Experimental Results

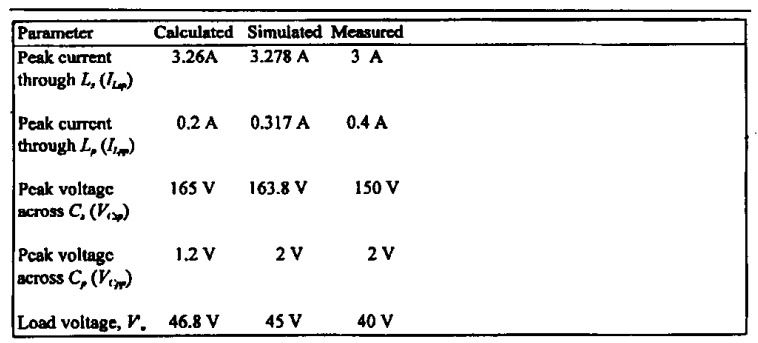

Note: Details of converter are given in Fig. 7, supply voltage $2 E=100 \mathrm{~V}$, full load $R_{L}^{\prime}=22 \mathrm{Ohms}$, switching frequency $f_{s}=$ $100 \mathrm{kHz}$.

the components used in the parallel branch draw very small current. By placing the parallel branch $\left(L_{p} C_{p}\right)$ on the secondary-side, the leakage inductances of the $\mathrm{HF}$ transformer can also be used as part of resonating inductances. If $\left(L_{p} C_{p}\right)$ is placed on a tertiary winding [16, Fig. 2(b)], then the leakage inductances can be used as part of $L_{s}$ and $L_{p}$. The converter proposed in this paper is ideally suited for high voltage output applications due to the use of capacitive output filter. If the parallel inductor $L_{p}$ is shorted, then the converter becomes LCC-type converter with capacitive output filter [18]. If the parallel capacitor $C_{p}$ is shorted, then the converter becomes LCL-type converter with capacitive output filter [19-21]. The steady-state performance characteristics of the (LC)(LC)-type converter designed in this paper are very close to those of LCL-type converter with capacitive output filter. The transient performance of the converter has to be investigated in future work. But preliminary studies show that step changes in load causes a dc current in the parallel branch for the LCL-type converter, whereas (LC)(LC)-type converter does not have this dc component due to the presence of $C_{p}$.
The complex ac circuit analysis presented looses accuracy in predicting the results at reduced load currents due to deviation of the waveforms from sinusoidal approximation. However, designing the converter at full load using approximate analysis and then using SPICE simulation to predict the performance of the converter simplifies the design procedure. Further work is under progress to analyze the converter using exact method and to operate the converter in fixed-frequency mode.

A. K. S. BHAT
Department of Electrical Engineering
University of Victoria
P.O. Box 3055, MS 8610
Victoria, B.C., V8W 3P6
Canada
A. BISWAS
B. S. R. IYENGAR
Department of Electrical Engineering
Indian Institute of Science
Bangalore-560012
India

REFERENCES

[1] Sum, K. K. (1988) Recent developments in resonant power conversion. Intertech Comm. Inc., 1988.

[2] Ranganathan, V. T., et al. (1982) A regulated dc-dc voltage source converter using a high-frequency link. IEEE Transactions on Industry Applications, IA-18, 3 (May/June 1982), 279-287.

[3] Bhat, A. K. S., and Dewan, S. B. (1987) Analysis and design of a high-frequency link resonant converter using LCC-type commutation. IEEE Transactions on Power Electronics, PE-2, 4 (Oct. 1987), 291-301.

[4] Chen, J., and Bonert, R. (1983) Load independent AC/DC power supply for high frequencies with sine-wave output. IEEE Transactions on Industry Applications, IA-19, 2 (Mar./Apr. 1983), 223-227.

[5] Steigerwald, R. L. (1988) A comparison of half-bridge resonant converter topologies. IEEE Transactions on Power Electronics, 3, 2 (Apr. 1988), 174-182.

[6] Johnson, S. D., Witulski, A. F., and Erickson, R. W. (1987) A comparison of resonant converter topologies in high voltage DC applications. In IEEE Applied Power Electronics Conference Record, (1987), 145-156.

[7] Muroyama, S., and Sakakibara, K. (1982) Characteristics of a new series resonant converter In Proceedings of IEEE International Telecommunications Energy Conference (INTELEC), (1982), 111-116.

[8] Kuwata, Y., Ohashi, Y., and Yotsumoto, K. (1987) Characteristics of a new series resonant converter with a parallel resonant circuit. In Proceedings of IEEE International Telecommunications Energy Conference (INTELEC), (1987), 204-210. 
[9] Bhat, A. K. S. (1991)

A unified approach for the steady-state analysis of resonant converters.

IEEE Transactions on Industrial Electronics, 38, 4 (Aug. 1991), 251-259.

[10] Jain, P. (1989)

A $20 \mathrm{kHz}$ hybrid resonant power source for the space station.

IEEE Transactions on Aerospace and Electronic Systems, 25, 4 (July 1989), 491-496.

[11] Jain, P., Bannard, D., and Cardella, M. (1992)

A phase-shift modulated double tuned resonant DC/DC converter: Analysis and experimental results. In Proceedings of IEEE Applied Power Electronics Conference, (1992), 90-97.

[12] Rosenberg, S. A., and Dewan, S. B. (1977)

An inverter/cycloconverter system for variable frequency, variable voltage, ac power supplies.

In Proceedings of IEEE IAS International Semiconductor Power Conference, (1977), 247-255.

[13] Baterseh, I., and Lee, C. Q. (1991)

Steady-state analysis of the parallel resonant converter with LLCC-type commutation network.

IEEE Transactions on Power Electronics, 6, 3 (July 1991), 525-538.

[14] Bhat, A. K. S., and Dewan, S. B. (1989)

A generalized approach for the steady-state analysis of resonant inverters.

IEEE Transactions on Industry Applications, 25, 2 (Mar./Apr. 1989), 326-338.

[15] Bhat, A. K. S. (1990)

Analysis and design of a modified series resonant converter.

In IEEE Applied Power Electronics Conference Record, (1990), 594-600.

[16] Bhat, A. K. S. (1991)

Analysis and design of a parallel resonant converter with the resonating capacitor placed on a tertiary winding. In IEEE Industry Application Society Conference Record, (Oct. 1991), 990-995.

[17] Biswas, A. (1993)

Analysis and design of (LC)(LC)-type series-parallel resonant converter.

M.E. project report, Department of Electrical

Engineering, Indian Institute of Science, Bangalore, Feb. 1993.

[18] Bhat, A. K. S. (1991)

Analysis and design of a series-parallel resonant converter with capacitive output filter.

IEEE Transactions on Industry Applications, 27, 3

(May/June 1991), 523-530.

[19] Severns, R. (1990)

Topologies for three element resonant converters. In IEEE Applied Power Electronics Conference Record, (Mar. 1990), 712-722.

[20] Schmidtner, E. G. (1988)

A new high frequency resonant converter topology.

In High Frequency Power Conversion Conference Record, (1988), 390-403.

[21] Bhat, A. K. S. (1990)

Analysis and design of LCL-type series resonant converter In Proceedings of IEEE International Telecommunications Energy Conference (INTELEC), (1990), 172-178.
Improving Performance in Pulse Radar Detection Using Neural Networks

A new approach using a multilayered feed forward neural network for pulse compression is presented. The 13 element Barker code was used as the signal code. In training this network, the extended Kalman filtering (EKF)-based learning algorithm which has faster convergence speed than the conventional backpropagation (BP) algorithm was used. This approach has yielded output peak signal to sidelobe ratios which are much superior to those obtained with the BP algorithm. Further, for use of this neural network for real time processing, parallel implementation of the EKF-based learning algorithm is indispensable. Therefore, parallel implementation of the EKF-based learning algorithm on a network of three transputers also has been developed.

\section{INTRODUCTION}

Pulse compression technique [1] is always used to improve the performance in pulse radar detection. In practice, two different approaches are used to obtain the pulse compression. The first one is to use a matched filter, in which codes with small sidelobes in their autocorrelation functions are used. The second approach is to use inverse filters of two kinds, viz., nonrecursive time invariant causal filter [2] and recursive time variant filter [3].

A new approach using a multilayered neural network that yields much better signal-to-sidelobe ratio (the ratio of peak signal to maximum sidelobe) than the traditional approaches has been reported in [4]. This approach also has an advantage of robustness that is typical of multilayered neural networks. In this approach, the 13 element Barker code [1] which has the sequence $[1,1,1,1,1,-1,-1,1,1,-1,1,-1,1]$ and the maximum length sequences ( $m$-sequences) of lengths 15, 31, and 63 (all of them are single period) [1] were used as the signal codes, and four networks were implemented, respectively. Each of the networks used had $n$ input nodes (where $n$ is the code length), three hidden nodes, and a single output node.

The BP algorithm, which is the most popular learning algorithm for training neural networks, was used for training the network. The training set for each network comprised of just the time-shifted sequences with magnitudes \pm 1 of the code adopted. The desired

Manuscript received October 20, 1993; revised July 27, 1994.

IEEE Log No. T-AES/31/3/12744.

0018-9251/95/\$4.00 (C) 1995 IEEE 